\title{
A adoção de práticas de Inovação Aberta pelas pequenas e médias empresas: um estudo empírico
}

\author{
Open Innovation practices held by small and medium-sized enterprises: an empirical \\ study
}

\author{
Ana Clara Cândido ${ }^{1}$ \\ Cristina Souza ${ }^{2}$
}

Artigo submetido em mai./2015 e aceito para publicação em ago./2015.

\section{RESUMO}

O presente estudo tem como principal objetivo estudar a adoção de práticas de inovação aberta em pequenas e médias empresas (PMEs). A Inovação Aberta é atualmente reconhecida como uma alteração de paradigma na gestão da inovação. Ao longo dos últimos anos, vários estudos empíricos confirmaram os resultados positivos da adoção do modelo aberto. Os primeiros estudos se basearam na análise de casos de grandes empresas. Entretanto, alguns estudos recentes foram aplicados em PMEs constatando resultados favoráveis também neste contexto. Contudo, ainda existe uma escassez de estudos sobre as práticas efetivamente adotadas por estas empresas. Sendo assim, a principal contribuição do presente estudo reside na apresentação de evidências e reflexões sobre a adoção do modelo em PMEs brasileiras, mostrando que a viabilidade da Inovação Aberta não só nas grandes empresas. A realização da análise empírica recorreu à abordagem qualitativa da Análise de Conteúdo, na qual três principais etapas foram realizadas: Pré-análise, Descrição Analítica e Interpretação. Os dados foram coletados a partir da realização de entrevistas com gestores e diretores de PMEs brasileiras. Os resultados empíricos obtidos neste estudo permitem identificar quatro tipos de práticas que são, de fato, caracterizadas pelo modelo de Inovação Aberta: envolvimento do cliente; externalização de Pesquisa e Desenvolvimento (P\&D); criação de novas empresas; externalização das competências de mercado e estão sendo utilizadas por PMEs.

Palavras-chave: Inovação Aberta. Parcerias Estratégicas. Pequenas e Médias Empresas.

\begin{abstract}
This study aims to study the adoption of open innovation practices in small and medium-sized enterprises (SMEs). Open Innovation is currently considered as a new paradigm in the area of innovation management. Over the past few years, several empirical studies have identified the positive effects of the adoption of the open model. The first studies focused on the case of large companies. More recently, some studies address the case of SMEs, but there is still a need to provide empirical evidence on the practices adopted by these companies. The current study contributes to fill this gap, providing evidence on the adoption of open innovation by Brazilian SMEs and showing the positive effects of this model also for SMEs. The study uses a qualitative method based on Content Analysis.. We interviewed managers and CEOs in Brazilian companies. The results of this study identify four practices types, that are, indeed, characteristic of Open Innovation model: customer involvement; Research and Development $(R \& D)$ externalization; creation of new enterprises; and externalization market competencies.
\end{abstract}

\footnotetext{
${ }^{1}$ Doutora em Avaliação de Tecnologia - Universidade Nova de Lisboa (FCT-UNL). Atualmente é pós doutoranda na Universidade Regional de Blumenau (FURB). Pesquisadora Associada no Inesc P\&D Brasil e no Centro Interdisciplinar de Ciências Sociais e Humanas (CICS.NOVA). Sua pesquisa é focada em gestão da inovação, inovação aberta e redes de colaboração. ana.candido@campus.fct.unl.pt

${ }^{2}$ Investigadora no DINÂMIA'CET-IUL e professora auxiliar convidada do ISCTE-IUL (Lisboa, Portugal). Mestre em Economia e Gestão de Ciência e Tecnologia e Doutora em Economia (ISEG / UTL, Lisboa). Sua pesquisa é focada nos processos de inovação, criação e circulação de conhecimento e empreendedorismo.

cristina.sousa@iscte.pt
} 
Revista Tecnologia e Sociedade, Curitiba, v. 11, n. 23, 2015

ISSN (versão online): 1984-3526

ISSN (versão impressa): 1809-0044

Keywords: Open Innovation. Strategic Alliances. Small and medium-sized enterprises.

\section{INTRODUÇÃO}

O atual dinamismo do mercado e a velocidade das alterações tecnológicas obrigam as empresas a buscarem novas formas de ganhar competitividade. Assim, a relevância de estudar o modelo de Inovação Aberta reside, sobretudo, no importante papel que atualmente desempenha nos processos de inovação das empresas. Pelo seu reconhecimento no campo da inovação, muitos estudos sobre a evolução do modelo e sua relação com outros temas foram e estão sendo realizados (LAURSEN e SALTER, 2006; DITTRICH e DUYSTERS, 2007; WEST e BOGERS, 2014).

Apesar de o conceito de Inovação Aberta ser recente, Chesbrough (2003) constrói a sua teoria a partir de conceitos desenvolvidos nas décadas de 80 e 90 (DAHLANDER; GANN, 2010). Um desses conceitos é o de ativos complementares desenvolvido por Teece (1986).

A ideia central é que o sucesso de uma estratégia de inovação não depende apenas da capacidade para gerar a inovação, sendo fortemente determinado por um conjunto de infraestruturas e capacidades que permitem o sucesso da comercialização e distribuição dessa inovação no mercado. Acontece que, frequentemente, a empresa que gerou a inovação não controla esses ativos complementares, sendo necessário o estabelecimento de parcerias com outras organizações (ROTHAERMEL, 2001).

O reconhecimento da existência de diferentes fontes de conhecimento e de inovação, internas e externas à empresa, também não é recente (VON HIPPEL, 1986). Por exemplo, Napolitano (1989), refere que a empresa pode inovar a partir de recursos internos (P\&D interna, engenharia de produtos e processos e contributos dos seus colaboradores) e externos (aquisição de tecnologia, matéria-prima e produtos intermédios, relacionamento com clientes e fornecedores, observação e análise de concorrentes, contratação de pessoal, interação com universidades, consulta de bases de dados de publicações e patentes, etc.).

A literatura também refere a necessidade de conjugar estas diferentes fontes externas e internas de conhecimento e inovação, como fica patente no conceito de capacidade de absorção (COHEN E LEVINTHAL, 1989, 1990). Para estes autores, o 
sucesso da estratégia de inovação está associado à capacidade de reconhecer o valor de um novo conhecimento, de assimilá-lo e de aplicá-lo de forma comercial. Sem esta capacidade a empresa não consegue transformar conhecimento gerado no seu exterior em inovações com sucesso comercial.

Este artigo tem como principal objetivo estudar a adoção de práticas de inovação aberta em pequenas e médias empresas (PMEs). Esta temática apresentase atual e relevante (CHESBROUGH, 2003; CHESBROUGH E CROWTHER, 2006; VANHAVERBEKE et al. 2012) e responde a diversos apelos à necessidade de ampliação de estudos empíricos em diferentes contextos (HUIZINGH, 2011; DAHLANDER E GANN, 2010; VANHAVERBEKE et al., 2012). Sendo assim, a principal contribuição do presente estudo reside na apresentação de evidências e reflexões sobre a adoção do modelo em PMEs, mostrando que a viabilidade da Inovação Aberta não ocorre só nas grandes empresas. Além disso, o entendimento das implicações da adoção do modelo em PME pode contribuir para a formulação de um modelo para sistematização deste processo.

O artigo começa com a apresentação do modelo de Inovação Aberta, salientando-se as suas principais características e diferenças face ao modelo de Inovação Fechada. Segue-se a revisão da literatura sobre a adoção da Inovação Aberta em PMEs, onde se salientam os potenciais benefícios e desafios para este tipo de empresas. Depois são apresentados os procedimentos metodológicos usados na análise empírica. $\mathrm{O}$ artigo prossegue com a apresentação da evidência empírica sobre a adoção de práticas de Inovação Aberta em PMEs brasileiras e termina com a sistematização dos resultados.

\section{DA INOVAÇÃO FECHADA À INOVAÇÃO ABERTA}

O modelo de Inovação Aberta é apresentado em contraste com o modelo de Inovação Fechada (Closed Innovation), onde a empresa que obtém maior vantagem competitiva é aquela que possui os mais sofisticados laboratórios de P\&D e realiza elevados investimentos para manter esta estrutura. Esta era a forma mais comum de chegar a novas descobertas, introduzir inovações e obter uma posição de destaque no mercado ao longo do século XX (CHESBROUGH, 2003; 2004; GANN, 2004; SMITH, 2004; HEMPHILL, 2005; BLAU, 2007). 
Revista Tecnologia e Sociedade, Curitiba, v. 11, n. 23, 2015

Cabe sublinhar que a autoria do conceito de Inovação Aberta é atribuida a Chesbrough (2003), para quem:

\begin{abstract}
"A inovação aberta é o paradigma que supõe que as empresas podem e devem usar ideias externas da mesma forma que usam ideias internas e caminhos internos e externos para o mercado à medida que as empresas buscam aperfeiçoar a sua tecnologia. A inovação aberta combina ideias internas e externas em arquiteturas e sistemas cujos requerimentos são definidos por um modelo de negócio. [...] A inovação aberta supõe que ideias internas podem ser também levadas ao mercado por meio de canais externos, fora dos negócios normais da firma, a fim de gerar valor adicional" (CHESBROUGH, 2003,p. 8).
\end{abstract}

Assim, o mérito da contribuição de Chesbrough (2003) é, sobretudo, o de sublinhar a crescente adesão das empresas a estratégias de inovação baseadas nesta "abertura" e a construção de um quadro de análise que permitiu relacionar e integrar conceitos relevantes para a gestão da inovação que anteriormente se encontravam dispersos, como mencionado na introdução deste artigo.

Ao longo das últimas décadas têm-se observado vários casos de insucesso de empresas consideradas fortes em termos de capacidade interna de P\&D. Com o atual entendimento sobre as práticas de gestão da inovação, seria possível listar uma série de equívocos cometidos na gestão de tais empresas ao longo dos anos. Um exemplo clássico é o caso da Xerox Corporation e o seu laboratório PARC (Palo Alto Research Center) que possuía uma forte estrutura interna de P\&D. Porém, muitas das valiosas inovações desenvolvidas não tinham aplicação para a Xerox e permaneceram guardadas para o caso de ser identificada alguma possível aplicação (CHESBROUGH, 2003).

Com o modelo de Inovação Aberta, esta falta de aproveitamento das inovações geradas internamente teria sido evitada, pois poderiam ter sido utilizadas como um ativo estratégico e comercializadas, permitindo a obtenção de lucros (CHESBROUGH, 2003). A experiência da Procter \& Gamble demonstra esta situação: as ideias geradas nos seus laboratórios e que não são aplicadas internamente ficam em espera durante três anos e, se após este período, não tiverem sido aproveitadas internamente, então poderão ser comercializadas a outras empresas.

De acordo com Chesbrough (2003) os fatores que levaram à emergência do modelo aberto são: 
- Crescente mobilidade de mão-de-obra de pessoas altamente experientes e capacitadas, que ao deixarem uma empresa na qual trabalharam por muito tempo levam consigo o conhecimento e as competências adquiridas.

- Associado ao ponto anterior verifica-se o aumento da quantidade de formações, proporcionado pela graduação e pela pós-graduação, a qual muitos colaboradores tiveram a oportunidade de realizar. Esta situação permitiu difundir o conhecimento desenvolvido nos laboratórios de pesquisa para diferentes ambientes e empresas, independentemente do seu tamanho e esforço em inovar.

- Crescente presença do capital de risco que facilitou a criação de novas empresas.

- O aumento da velocidade de alteração do mercado, com a comercialização cada vez mais rápida de muitos produtos e serviços, fazendo a posição de liderança de determinada tecnologia ter tempos mais reduzidos.

No modelo de Inovação Aberta, o conhecimento que uma empresa obtém através das suas pesquisas não tem que ficar restrito aos seus caminhos internos para o mercado, caso contrário, certamente algumas inovações deixariam de ser aproveitadas. Ou ainda "Os fatores de erosão que abalam a inovação fechada igualmente abalam a preferência das companhias por deixar ideias na gaveta até que possam ser utilizadas internamente" (CHESBROUGH, 2003, p. 13).

Parece existir consenso sobre a necessidade de conjugar a existência de capacidade interna com o desenvolvimento do processo de inovação. Enfatiza-se a importância das empresas terem, no mínimo, uma estrutura de base da inovação para que possam articular-se de maneira proveitosa com os seus parceiros. Cohen e Levinthal (1989; 1990) designam pelo termo "capacidade de absorção" esta necessidade das empresas estarem preparadas para receber ou absorver o conhecimento de fora. Neste sentido, sugerem o papel duplo dos investimentos em P\&D: desenvolver inovações internamente e a capacidade de absorção necessária para acompanhar e avaliar o desenvolvimento fora de suas fronteiras. Nas palavras de Dyer e Singh (2003, p.320) "A capacidade de explorar fontes externas de conhecimento depende, em grande parte, de um conhecimento anterior relacionado ou da "capacidade de absorção" de conhecimento". 
A importância da sistematização do processo de inovação internamente é retomada como um fator crucial para o estabelecimento eficiente de ações colaborativas. A literatura afirma que é desta maneira que o modelo de Inovação Aberta parece ter mais chances de sucesso, ou seja, quando a empresa já possui iniciativas consistentes de estruturação de inovação internamente. Esta estrutura interna de inovação reflete-se na eficiência da empresa em lidar com múltiplos aspectos, tais como: questões de direitos de PI; recursos financeiros para inovação; sistema de proteção legal; capital intelectual; processos de aprendizagem.

Ainda referente à necessidade de estruturação para a adoção mais eficiente do modelo de Inovação Aberta, o estudo de Wang, Vanhaverbeke e Roijakkers (2012) centra-se no âmbito macro através da análise sobre o Sistema Nacional de Inovação e conclui que este precisa ser ajustado quando as empresas inseridas em seu contexto utilizam o modelo aberto. Nas palavras de Wang, Vanhaverbeke e Roijakkers:

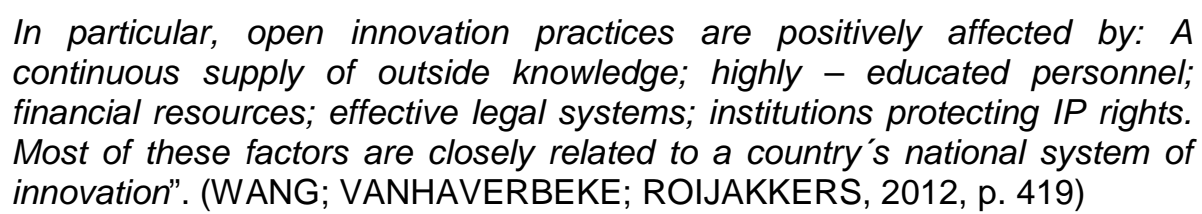

A dúvida que muitas vezes assola o ambiente empresarial é sobre a medida certa para os investimentos internos em P\&D e o grau de abertura para o ambiente externo. Sobre esta situação, Dahlander e Gann (2010), ao explorarem cuidadosamente os diferentes tipos de abertura, afirmam que capacidade interna e externa são complementares e o balanço entre elas deve ser medido tendo em consideração a estratégia que a empresa pretende utilizar. Os autores argumentam ainda que ter uma estrutura de $P \& D$ interna pode facilitar a interação com determinados parceiros.

\section{A INOVAÇÃO ABERTA EM EMPRESAS DE DIFERENTES DIMENSÕES}

A experiência da adoção do modelo de Inovação Aberta difere significativamente consoante $\mathrm{o}$ tipo de indústria e a dimensão da empresa (CHESBROUGH, 2003). Como mencionado anteriormente, a maioria dos estudos sobre o assunto baseia-se em casos isolados da adoção do modelo por grandes empresas (DSM, IBM, Procter \& Gamble, FiatMio, Natura, TOTVS). 
Revista Tecnologia e Sociedade, Curitiba, v. 11, n. 23, 2015

Embora em pequeno número, alguns estudos recentes têm analisado o potencial das PMEs na obtenção de melhores práticas e ganhos advindos da adoção do modelo aberto e defendem a utilização do modelo por parte destas (VRANDEA et al., 2009; VANHAVERBEKE et al., 2012). Embora se reconheçam os potenciais benefícios do modelo para estas empresas, a literatura ainda carece de estudos empíricos que analisem a aplicação do modelo pelas PMEs.

Esta insuficiência de estudos empíricos que abordem o caso das PMEs é relatada por Lee et al. (2010) ressaltando que estatisticamente não existe comprovação de que as grandes empresas são melhores em termos de inovação do que as PMEs.

Nas PMEs, os benefícios de migração para o modelo de Inovação Aberta diferem dos benefícios clássicos que são percebidos nas grandes empresas. O estudo desenvolvido por Laursen e Salter (2006) observa que as PMEs poderão recorrer/combinar um número menor de práticas de Inovação Aberta, mas isto não significa que não seja importante adotar um conjunto de ações que assegurem a gestão da Inovação Aberta.

Neste sentido, a flexibilidade nomeadamente para a tomada de decisão nas PMEs pode ser uma vantagem no processo de adoção do modelo aberto e consequentemente pode acelerar o seu processo de inovação. Conforme ressaltam Lee et al. (2010), algumas PMEs possuem capacidade suficiente para fazer a gestão de todo o processo de inovação. Contudo, as PMEs podem exibir escassez de outros recursos indispensáveis à transformação de invenções em novos processos ou produtos (manufatura, distribuição, marketing, etc) (VANHAVERBEKE et al. 2012). Desta forma, a interação com outras empresas e organizações e os processo colaborativos podem ser reforçados quer pela de capacidades internas de gestão da inovação, quer pela ausência de recursos no interior da empresa.

Muitas vezes o desafio de adquirir tecnologias externas é maior para as pequenas empresas. Nas seções anteriores destacou-se a importância de uma capacidade interna de P\&D para garantir uma boa interação com o ambiente externo. Saber identificar, transferir e absorver ideias e/ou tecnologias externas é por vezes um empecilho para as pequenas empresas. Isto é consequência da falta de visão de negócio da empresa, sendo imprescindível 0 envolvimento dos colaboradores neste processo (KIRSCHBAUM, 2005). 
Revista Tecnologia e Sociedade, Curitiba, v. 11, n. 23, 2015

Relativamente aos desafios enfrentados pelas PMEs e pelas grandes empresas na utilização do modelo de Inovação Aberta, o estudo de Lee et al. (2010) apresenta uma comparação sobre as principais diferenças observadas na percepção de dificuldades na implementação do modelo aberto, que se encontram sistematizadas na Tabela 1. No caso das dificuldades enfrentadas pelas PMEs notase aspectos que podem ser atenuados através da interação em redes de colaboração, como é o caso das dificuldades com recursos humanos e falta de infraestrutura.

\begin{tabular}{|l|l|l|}
\hline \multicolumn{2}{|c|}{ Pequenas e Médias empresas } & \multicolumn{2}{c|}{ Grandes empresas } \\
\hline 10 & $\begin{array}{l}\text { Dificuldade para encontrar mão de obra } \\
\text { adequada para o mercado de trabalho }\end{array}$ & $\begin{array}{l}\text { Estrutura de mercado monopolista ou } \\
\text { oligopolista }\end{array}$ \\
\hline 2o & $\begin{array}{l}\text { Pouca mão de obra adequada dentro } \\
\text { da empresa }\end{array}$ & $\begin{array}{l}\text { Dificuldade de financiamento, devido aos } \\
\text { altos custos de comercialização da } \\
\text { inovação }\end{array}$ \\
\hline 3o & $\begin{array}{l}\text { Incerteza do mercado em produtos } \\
\text { inovadores }\end{array}$ & $\begin{array}{l}\text { Dificuldade para encontrar mão de obra } \\
\text { adequada no mercado de trabalho }\end{array}$ \\
\hline 4- & $\begin{array}{l}\text { Possibilidades de imitação de inovação } \\
\text { tecnológica }\end{array}$ & $\begin{array}{l}\text { Falta de necessidade de inovação } \\
\text { adicional }\end{array}$ \\
\hline 5o & $\begin{array}{l}\text { Pouca capacidade de planejamento e } \\
\text { gestão de P\&D }\end{array}$ & $\begin{array}{l}\text { Frequente rotatividade de recursos } \\
\text { humanos (geralmente para P\&D) }\end{array}$ \\
\hline
\end{tabular}

Tabela 1. Dificuldades enfrentadas pelas PMEs e pelas grandes empresas em Inovação Aberta. Fonte: Adaptado de Lee et al. (2010, p. 296)

Outro ponto de partida importante para o sucesso da inovação, em geral, e do modelo aberto, em particular, é a definição do modelo de negócio. Esta é uma questão que vale para todas as empresas, independente do seu tamanho. Interagir com os seus próprios clientes na tentativa de entendê-los e procurar conhecer suas preferências e incorporá-las no desenvolvimento de inovações é um indicativo de início do modelo aberto (SPITHOVEN; VANHAVERBEKE; ROIJAKKERS, 2013). É importante destacar que a definição de uma estratégia para o modelo de negócio nem sempre é uma tarefa simples para as empresas e a interação com os clientes pode ter uma contribuição importante neste processo. Uma boa definição do modelo de negócio pode ser a saída para muitas empresas conseguirem um diferencial no mercado, oferecerem produtos de valor agregado e tentarem garantir o crescimento sustentável. Entretanto, cabe ressaltar que o modelo de negócio não é uma 
Revista Tecnologia e Sociedade, Curitiba, v. 11, n. 23, 2015

definição permanente, pelo que a empresa precisa constantemente de se reinventar e repensar o seu modelo de negócio.

Conforme Vanhaverbeke et al. (2012) entre as principais barreiras observadas no cenário da Inovação Aberta para as PMEs, destacam-se:

- Restrições financeiras

- Rápida imitação da inovação pelos concorrentes

- Falta de proteção da Propriedade Intelectual

- Ausência de ativos complementares (Ex: acesso aos canais de distribuição e estrutura fabril adequada)

- Habilidades de produção e design pouco desenvolvidas

- Habilidades gerenciais para comercialização de seus produtos de forma profissional e estratégica

Enquanto algumas PMEs julgam que a Inovação Aberta é assunto para as grandes empresas, os resultados de estudos empíricos têm revelado o potencial deste modelo novo para as empresas de menor dimensão. "SMEs have good reasons to reach out to different partners to develop and commercialize new business ideas" (VANHAVERBEKE et al. 2012, p. 54). Em alguns casos, evidenciam-se aspectos que demonstram vantagens na adoção pelas PMEs em relação às grandes empresas.

No entanto, conforme observado por Lee et al. (2010) enquanto muitos estudos têm afirmado que as PMEs apresentam maior produtividade em termos de P\&D (com ressalvas de variações específicas das diversas indústrias) ainda há muito debate sobre as desvantagens pela falta de recursos materiais que estas empresas enfrentam.

\section{PROCEDIMENTOS METODOLÓGICOS}

\section{CARACTERIZAÇÃO DO UNIVERSO ANALISADO}

No universo escolhido para aplicação do estudo, a amostra é composta por empresas participantes da Associação de Empresas de Tecnologia de Santa Catarina (ACATE) que prestam serviços baseados em cloud computing. 
A estrutura da ACATE está organizada em grupos chamados de "verticais de negócios" com a finalidade de aproximar as empresas que atuam em mercados semelhantes estimulando o associativismo e o relacionamento entre as empresas.

Até ao presente momento, a ACATE conta com doze verticais em funcionamento para empresas que desenvolvem e comercializam produtos computacionais. Assim, o presente estudo foi aplicado na vertical de cloud computing, onde foram entrevistadas nove empresas associadas. Todas as empresas entrevistadas são PMEs. Por questões de privacidade, o nome das empresas entrevistadas não será divulgado.

\section{COLETA DE DADOS}

O presente artigo recorre a dados primários coletados através de entrevistas com (diretores, gestores e CEOs). As entrevistas foram suportadas por roteiros semiestruturados e centraram-se na obtenção de informações e percepções sobre a experiência e práticas de Inovação Aberta associadas a parcerias estratégicas pelas empresas analisadas. O conceito de roteiros semiestruturados corresponde bem com a característica do estudo, pois constitui a elaboração de um roteiro constituído por perguntas principais a partir da revisão teórica já realizada.

\section{ANÁLISE DE DADOS}

Para a aplicação do presente estudo empírico recorreu-se a Análise de Conteúdo. Esta análise é suportada pelo conhecimento adquirido ao longo da revisão de literatura sobre o tema de Gestão da Inovação e Inovação Aberta.

De acordo com Bardin (2008), a análise de conteúdo pode ser:

- quantitativa, tendo como informação de base a frequência dos padrões analisados.

- qualitativa para identificar padrões que possam surgir dos documentos analisados.

No presente estudo, é usada a abordagem qualitativa. Esta incide sobre a transcrição das entrevistas. Seguindo Bardin (2008), o processo de análise de conteúdo foi conduzido em 3 etapas básicas: 
Pré-análise - organização do material (transcrição das entrevistas) e definição prévia das categorias. As categorias da análise foram definidas com base na revisão da literatura, nomeadamente sobre os desafios das PMEs na Inovação Aberta (DAHLANDER e GANN, 2010; VANDREA et al., 2009; VANHAVERBEKE et al 2012; ZENG et al 2010) e sobre a gestão de redes e processos colaborativos (OZMAN, 2009). Foram definidas 18 categorias de análise, encontrando-se intimamente associadas à própria estrutura da entrevista:

1. Formalização das estratégias de inovação

2. Capacidades internas de inovação

3. Capacidades de gestão da rede

4. Nível de abertura

5. Dimensão do processo de Inovação Aberta (Inbound e Outbound)

6. Tipos de práticas de Inovação Aberta

7. Envolvimento dos colaboradores nas práticas de inovação

8. Existências de alianças estratégias

9. Tipos de parceiros

10. Motivações para as alianças

11. Resultados obtidos

12. Formas de relacionamento: formalização, tipo de contato e frequência

13. Origem da parceria

14. Barreiras e obstáculos na realização da parceria

15. Duração da parceria

16. Confiança no parceiro

17. Vantagens das práticas colaborativas

18. Desvantagens das práticas colaborativas

Descrição Analítica - construção de quadros de referências, leitura e procura por sínteses coincidentes e ideias divergentes. Foram categorizadas as afirmações dos entrevistados sobre as parcerias usando as 18 categorias pré-definidas. Assim, foram construídos quadros que suportaram a descrição dos resultados.

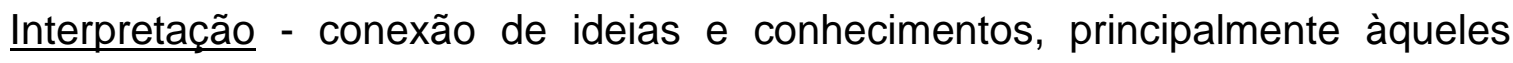
adquiridos ao longo do desenvolvimento do trabalho. Análise crítica dos resultados com base no seu contraste com o constructo teórico que permeia todo o trabalho. 


\section{ADOÇÃO DE PRÁTICAS DE INOVAÇÃO ABERTA: EVIDÊNCIA EMPÍRICA}

A análise do conteúdo das entrevistas permite constatar que algumas empresas mostraram maturidade no estabelecimento e gestão de suas parcerias. No entanto, nenhuma das empresas entrevistadas relatou ter um processo estruturado de Gestão da Inovação.

Portanto, há que ressaltar aqui que, embora as empresas nas quais foram identificadas práticas de Inovação Aberta não possuam processo formal de Gestão da Inovação, elas demonstraram ter experiência nas interações realizadas com seus parceiros. No entanto, parece existir um gap ainda no estabelecimento do processo colaborativo, englobando as negociações sobre os direitos e deveres dos envolvidos, consequentemente também sendo perceptível a falta de estratégias direcionadas à gestão de Propriedade Intelectual.

O envolvimento entre os parceiros ainda acontece de forma pontual, observando-se que, em todos os casos identificados, a prática foi originada por uma necessidade percebida pela empresa em fase mais avançada e não na fase da ideação ou mesmo na identificação de oportunidades. Assim, o envolvimento dos parceiros acontece, sobretudo, para suprir iniciativas em áreas nas quais as empresas avaliam não desenvolver internamente. Retomando o conceito de colaboração, ressalta-se a importância do envolvimento e do trabalho conjunto dos parceiros no planejamento, implementação e avaliação dos processos interorganizacionais para atingir objetivos comuns e consequentemente fortalecer as competências individuais dos envolvidos.

Estas questões são levantadas no sentido de reforçar que as estratégias colaborativas podem ser mais proativas no envolvimento de parceiros em fases iniciais, por exemplo, na identificação das oportunidades. O perfil das práticas identificadas deixa evidente o domínio existente de um dos parceiros, neste caso, das empresas entrevistadas. Não foram identificadas práticas que aconteceram de forma descentralizada e dinâmica, verificando-se pelo contrário, sempre um parceiro dominante (normalmente sendo este quem define o alinhamento da interação).

Por fim, as práticas analisadas permitem afirmar que existe sinergia entre os parceiros e a relação de confiança é de extrema importância tanto na escolha do parceiro, como no desenvolvimento das atividades. Entretanto, ainda existe um caminho a ser percorrido do ponto de vista da aprendizagem das práticas de 
Revista Tecnologia e Sociedade, Curitiba, v. 11, n. 23, 2015

Inovação Aberta. Pode-se notar que existe um aproveitamento dos benefícios gerados pelo modelo aberto, mas este ainda é administrado de forma aparentemente aleatória. Ou seja, não existe uma sistematização da estratégia de adoção do modelo aberto.

A questão que se coloca é o aproveitamento de outras práticas do modelo aberto que poderiam ainda ser utilizadas, evidentemente se alinhadas ao modelo de negócio da empresa. Não desvalorizando as práticas de Inovação Aberta que foram mencionadas, é certo que as interações têm ocorrido e a partir da experiência de interação cada empresa tem tirado lições sobre o desenvolvimento em parcerias.

\section{TIPOS DE PRÁTICAS DE INOVAÇÃO ABERTA OBSERVADAS}

Após a análise de conteúdo das informações obtidas na aplicação das entrevistas foi possível identificar quatro tipos de práticas de Inovação Aberta, conforme representado na Figura 1. Nesta seção apresenta-se apenas as parcerias mencionadas pelas empresas entrevistas que constituem, de fato, práticas de Inovação Aberta. Este resultado alerta para a necessidade de cautela na equiparação de práticas de colaboração e práticas de Inovação Aberta. Esta situação vai ao encontro da advertência de Lee et al.:

\footnotetext{
"simply using an external marketing agency does not mean open innovation at the commercialisation stage, as leaving a simple task to a specialised firm is not supposed to be an open innovation at the R\&D stage. Open innovation happens, only when a firm worked with another firm specialised in marketing, which involved actively in the collaboration, contributing a lot to the innovation process through market exploitation, market test, or customer needs analysis" (LEE et al., 2010, p. 292).
}

A partir do entendimento das práticas de Inovação Aberta, foram mencionadas, no total das entrevistas, 26 parcerias e destas foram identificadas 9 parcerias que utilizaram alguma prática característica do modelo aberto.

A análise de conteúdo permitiu igualmente identificar quatro tipos de práticas de Inovação Aberta que são usadas pelas empresas entrevistadas, conforme representado na Figura 1:

- Envolvimento do cliente

- Criação de novas empresas

- Externalização de Pesquisa e Desenvolvimento

- Externalização das competências de mercado 


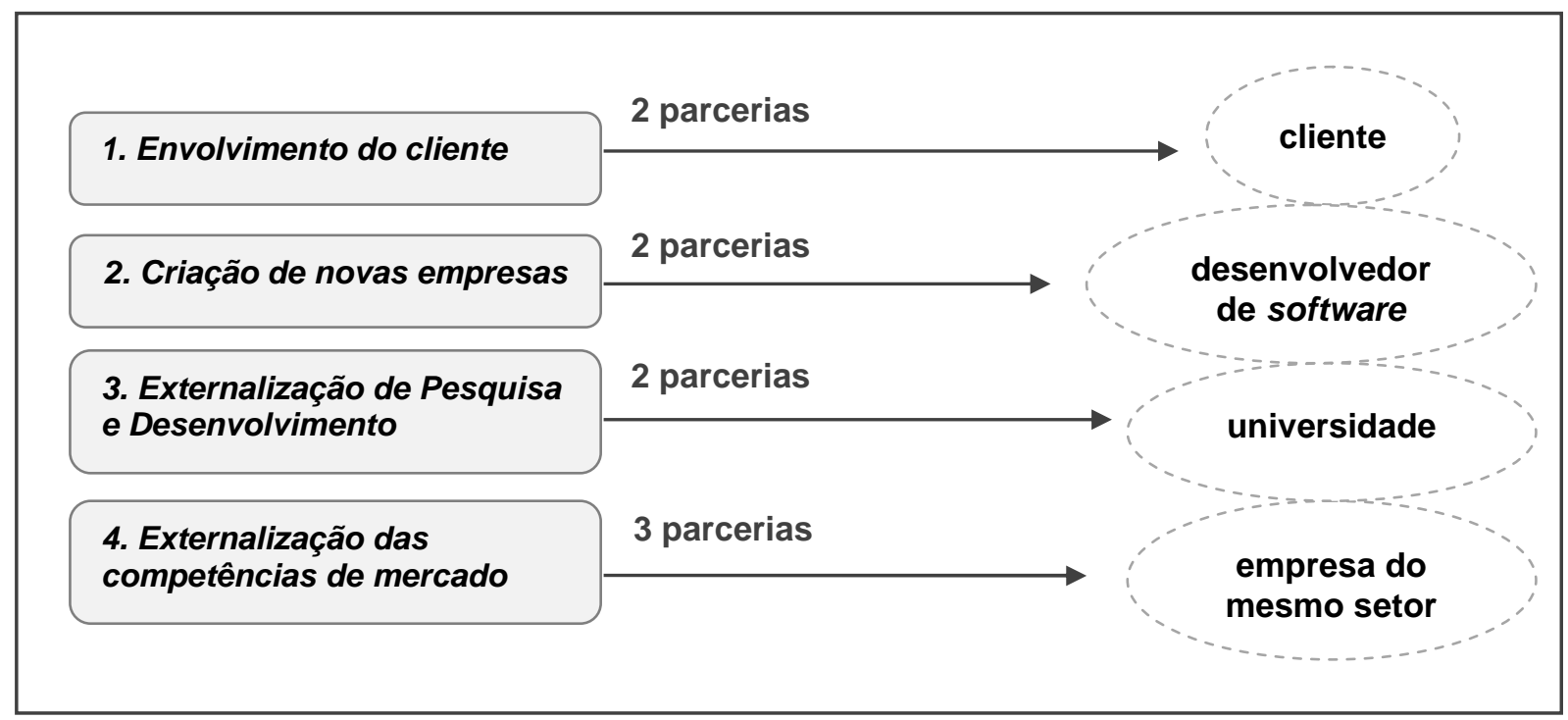

Figura 1 - Práticas de Inovação Aberta realizadas pelas PMEs. Fonte: Dados da pesquisa

- Envolvimento do cliente

Das nove empresas entrevistadas, duas delas mencionaram parcerias com os seus clientes. Desta forma, dois casos de práticas de Inovação Aberta foram contabilizados, pois se assume que estas interações envolveram o cliente ativamente no desenvolvimento de novos produtos.

Para uma destas empresas, o envolvimento do cliente no processo de inovação foi fundamentalmente motivado pela obtenção de conhecimento sobre as suas necessidades e preferências, em linha com Spithoven; Vanhaverbeke; Roijakkers (2013). De acordo com a empresa, tal conhecimento permite desenvolver uma solução tecnológica mais próxima da necessidade percebida pelo mercado, do qual o cliente tem um bom conhecimento. Apesar de já existir uma relação de confiança, optou-se por fazer um contrato jurídico para assegurar os direitos e deveres de cada uma das partes. A união de forças resultou em novos produtos para a empresa entrevistada.

No segundo caso, a empresa relatou que o envolvimento de clientes no desenvolvimento de um novo produto já é uma prática testada com outros clientes, com quem possui uma interação mais ativa. Aqui, houve uma mútua troca de interesses: o cliente tinha necessidade de competência específica para desenvolver um novo produto e a empresa identificou uma oportunidade de desenvolver esta solução com a expertise de mercado do cliente. Assim, o cliente ganhou, pois teve a sua necessidade atendida e de forma personalizada e a empresa, além de 
Revista Tecnologia e Sociedade, Curitiba, v. 11, n. 23, 2015

desenvolver um novo produto, teve a oportunidade de entrar num novo mercado e de adquirir novas competências. Neste caso, a empresa considera que o maior ganho não foi financeiro, mas sim a obtenção de conhecimento.

\section{- Criação de novas empresas}

Identificam-se duas práticas de Inovação Aberta que originaram novas empresas desenvolvedoras de soluções de software, que nasceram com o apoio de uma das empresas entrevistadas e são consideradas parcerias estratégicas para esta.

A principal motivação destas parcerias decorreu da oportunidade identificada por profissionais autônomos que tinham desejo de iniciar um novo negócio, porém não conseguiriam desenvolver seus produtos de forma isolada e lançaram-se no mercado à procura de parceiros. Portanto, a iniciativa desta interação não foi promovida pela empresa: na maioria das vezes este tipo de informação chega até à empresa através de indicação informal proveniente de colaboradores, amigos ou através de redes sociais. A partir disto, a empresa analisa o potencial do projeto a ser desenvolvido e quando julga ser interessante iniciar a parceria estipulam-se as tarefas, os direitos e os deveres. É feito um contrato social de abertura da empresa quando os planos de negócio estão em estágio mais avançado de desenvolvimento.

Importante salientar que não há investimentos financeiros por parte da empresa, mas sim a disponibilização de recursos de infraestrutura e conhecimento técnico. Os dois casos observados são parcerias ainda ativas, uma delas com início em 2009 e a outra em 2011.

- Externalização de Pesquisa e Desenvolvimento

Duas parcerias realizadas por uma mesma empresa são consideradas práticas de Inovação Aberta no âmbito da realização de atividades de P\&D, ambos os casos envolvendo interações com universidades. Juntamente com uma universidade americana, a empresa entrevistada começou a fazer adaptações em alguns produtos com potencial de vendas no exterior. A empresa chegou até esta universidade através de um programa de auxílio a empresas start-ups brasileiras. A oportunidade de aumentar a rede de relacionamento com parceiros internacionais foi um aspecto motivador para a empresa na definição da parceria. Antes do início da interação, houve encontros face-a-face, nos EUA e no Brasil, como forma de conhecerem os ambientes uma da outra e a partir disto formalizaram, por meio de contrato, os direitos e deveres de cada um dos envolvidos. Até o momento da 
Revista Tecnologia e Sociedade, Curitiba, v. 11, n. 23, 2015

realização da entrevista, este projeto conjunto encontrava-se em fase de desenvolvimento, sendo difícil fazer uma avaliação dos resultados alcançados.

A outra colaboração ocorreu com uma universidade brasileira no ano de 2011 e mesmo não tendo atingido os resultados esperados, a empresa relatou ter sido uma parceria estratégica. A partir da análise do conteúdo da entrevista, percebe-se que esta corresponde a uma prática de Inovação Aberta pois teve como objetivo a obtenção conhecimento da universidade para o desenvolvimento colaborativo de um novo produto. O alinhamento sobre as expectativas de cada um dos envolvidos não ficou claro no início da relação, que acabou por ser abandonada sem gerar qualquer resultado. O insucesso desta experiência ilustra a necessidade de competências na área da gestão das parcerias, nomeadamente ao nível da clarificação dos direitos e dos deveres dos parceiros.

- Externalização das competências de mercado

Três das empresas entrevistadas estabelecem relações comerciais entre si que configuram práticas de Inovação Aberta. Embora, a interação entre estas empresas não tenha surgido através da ACATE, visto que a vertical cloud computing ainda não existia, o fato de participarem deste grupo tende a fortalecer a relação entre elas. Os contatos entre estas empresas foram iniciados por uma delas com o intuito de firmar novas parcerias através de práticas de networking.

É possível observar uma estratégia proativa de identificação de parceiros, alinhada com a estratégia de crescimento da empresa, com o intuito de obter o conhecimento de mercado necessário ao desenvolvimento de novos produtos, de forma a aumentar a probabilidade de sucesso da sua comercialização. Paralelamente, os seus parceiros participam ativamente no processo de desenvolvimento do produto. Tratando-se, portanto, de uma prática de Inovação Aberta.

A utilização de mercados comuns foi outras das principais motivações, visto que ambas as empresas envolvidas na parceria oferecem produtos e soluções que atendem o mesmo público. Assim sendo, alguns produtos foram incorporados no portfólio um do outro.

Com base na experiência que a empresa possui pela realização de parcerias anteriores, o início da relação com as duas outras empresas passou por uma etapa de alinhamento das expectativas, bem como o estabelecimento de compromissos 
Revista Tecnologia e Sociedade, Curitiba, v. 11, n. 23, 2015

que as partes assumiriam no trabalho colaborativo. Após estas conversas iniciais, é feito um contrato para assegurar que as regras fiquem registadas e estabelecidas para todos.

A interação entre tais empresas encontra-se em estágio inicial, sendo difícil quantificar os resultados. Porém, uma destas empresas menciona que a parceria já contribuiu para o surgimento de quatro novos projetos de inovação, enquanto que a empresa parceira já observa alguns progressos ao nível da comercialização dos produtos.

\section{CONSIDERAÇÕES FINAIS}

A adoção do modelo de Inovação Aberta em grandes empresas atualmente já está em estágio de maturidade mais avançada do que a sua adoção pelas PMEs (SPITHOVEN; VANHAVERBEKE; ROIJAKKERS, 2013). Após as leituras sobre o tema e a aplicação das entrevistas, é possível afirmar que as empresas entrevistadas, embora de tamanho menor, estão cientes dos benefícios do modelo aberto.

O estudo de Vanhaverbeke et al., (2012, p.10) identifica a falta de visão sobre os benefícios do modelo de Inovação Aberta, concluindo que: "Most companies we interviewed were not interested in open innovation as such". O mesmo não pode ser afirmado com base nos resultados do presente estudo. No contexto analisado, a baixa utilização das práticas de Inovação Aberta não é originada por uma falta de interesse, mas sim por uma falta de conhecimento mais aprofundado sobre a forma de operacionalizar as práticas do modelo aberto. Ou seja, as empresas reconhecem os benefícios do modelo aberto, mas são desencorajadas a adotá-lo pela barreira da operacionalização apropriada ao seu tipo de negócio e estratégia.

Os resultados do estudo mostram que nem todas as parcerias identificadas pelas empresas se enquadram em práticas de Inovação Aberta. Desta forma, o presente artigo vai ao encontro do alerta realizado por Lee et al. (2010) para o perigo de se equiparar automaticamente Inovação Aberta com colaborações, sem analisar detalhadamente as formas e os objetivos que essas colaborações assumem.

A análise aprofundada das colaborações identificadas permitiu identificar quatro práticas de Inovação Aberta distintas: Envolvimento do cliente; Criação de 
Revista Tecnologia e Sociedade, Curitiba, v. 11, n. 23, 2015

novas empresas; Externalização de Pesquisa e Desenvolvimento; e Externalização das competências de mercado.

A adoção destas práticas de Inovação Aberta originou um conjunto de benefícios para as empresas. Entre estes benefícios encontram-se o desenvolvimento de novos produtos e a entrada em novos mercados, que permitem o crescimento da empresa e a obtenção de benefícios monetários. Adicionalmente, as empresas reportam benefícios associados ao acesso a recursos, competências e conhecimento vitais para o seu processo de inovação.

Mas nem sempre é fácil implementar o modelo de Inovação Aberta e nem sempre as iniciativas adotadas pelas empresas são bem sucedidas. Este estudo permite igualmente identificar um conjunto de dificuldades/desafios que estas PMEs enfrentam na implementação das práticas de Inovação Aberta. A principal dificuldade identificada relaciona-se com a forma de operacionalizar a adoção do modelo e o seu aproveitamento de maneira mais aprofundada e não apenas com necessidades pontuais. Ou seja, é preciso criar um contexto aberto para que possam identificar novas oportunidades e não apenas trabalhar sobre as necessidades já identificadas. Outra questão também percebida é a falta de alinhamento da gestão da Inovação Aberta com a estratégia da empresa. É preciso saber quais as informações que poderão disponibilizar aos agentes externos e quais deverão ser utilizadas de forma estritamente interna. Finalmente, os resultados salientam a necessidade de um clara definição dos papeis e das expectativas dos parceiros e da propriedade intelectual resultante da colaboração.

\section{REFERÊNCIAS}

BARDIN, L. Análise de Conteúdo. - 4. ed. Lisboa: Edições 70, 2008.

BLAU, J. Philips Tears Down Eindhoven R\&D Fence. Research Technology Management, v. 50(6), p. 9-10, 2007.

CHESBROUGH, Henry. Open Innovation: The New Imperative for Creating and Profiting from Technology. Boston: Harvard Business School Press, 2003.

CHESBROUGH, Henry. Managing Open Innovation. Industrial Research Institute, v. 47, p. 23-26, 2004.

CHESBROUGH, H., CROWTHER, A.K. Beyond high tech: early adopters of open innovation in other industries. R\&D Management, v.36 (3), p. 229-236, 2006. 
Revista Tecnologia e Sociedade, Curitiba, v. 11, n. 23, 2015

COHEN, W.M., LEVINTHAL, D.A. Innovation and learning: Two faces of R\&D. The Economic Journal, v. 99, p. 569-596, 1989.

COHEN, W.M., LEVINTHAL, D.A. Absorptive capacity: a new perspective on learning and innovation. Administrative Science Quarterly, v. 35 (1), p. 128-152, 1990.

DAHLANDER, L., GANN, D. How open is innovation? Research Policy, v. 39, p. 699-709, 2010.

DITTRICH, K., DUYSTERS, G. Networking as a Means to Strategy Change: The Case of Open Innovation in Mobile Telephony. The Journal of Product Innovation Management, v. 24, p. 510- 521, 2007.

DYER, J.H., SINGH, H. (2003). Utilizando alianças para construir vantagem competitiva em tecnologias emergentes. In: DAY, G.S., SCHOEMAKER, P.J.H., GUNTHER, R.E. Gestão de Tecnologias Emergentes: a visão de Wharton School. Porto Alegre: Bookman. 2003. p. 312-327.

GANN, D. Book review - Open Innovation: The New Imperative for Creating and Profiting from Technology, Research Policy, v. 10(1), p. 122-123, 2004.

HEMPHILL, T. Book review - Open innovation: The New Imperative for Creating and Profiting from Technology. Academy of Management Executive, v. 19, p. 164-165, 2005.

HUIZINGH, E.K.R.E. Open Innovation: State of the art and future perspectives. Technovation, v. 31 (1), p. 2-9, 2011.

KIRSCHBAUM, R. Open Innovation in Practice. Research Technology Management, v. 48(4), p. 24-28, 2005.

LAURSEN, K., SALTER, A. Open for innovation: the role of openness in explaining innovation performance among U.K. manufacturing firms. Strategic Management Journal, v. 27 , p. $131-150,2006$

LEE, S. et al. Open innovation in SMEs-an intermediated network model. Research Policy, v. 39(2), p. 290-300, 2010.

NAPOLITANO, G. Industrial Research and Sources of Innovation. A Cross-Industry Analysis of the Italian Manufacturing Firms. Columbia University, 1989.

ROTHAERMEL, F.T. Incumbent's advantage through exploiting complementary assets via interfirm cooperation. Strategic Management Journal, v. 22 (6-7), p. 687-699, 2001.

SMITH, P. Book review- Open innovation: The Open Innovation: The New Imperative for Creating and Profiting from Technology. Journal of Product Innovation Management, v. 21, p. 221-224, 2004.

SPITHOVEN, A., VANHAVERBEKE, W., ROIJAKKERS, N. Open innovation practices in SMEs and large enterprises. Small Business Economics, v. 41(3). p. 537-562, 2013.

TEECE, D.J. Profiting from technological innovation: implications for integration collaboration, licensing and public policy. Research Policy, v. 15, p. 285-305, 1986.

VANHAVERBEKE, Wim. et al. Open Innovation in SMEs: How can small companies and start-ups benefit from open innovation strategies? Research Report, 2012. 
Revista Tecnologia e Sociedade, Curitiba, v. 11, n. 23, 2015

ISSN (versão online): 1984-3526

ISSN (versão impressa): 1809-0044

VON HIPPEL, E. Lead Users: A Source of novel products concepts. Management Science, v. 32, p. 791-805, 1986.

VRANDEA, V. et al. Open innovation in SMEs: Trends, motives and management challenges. Technovation, v. 29, p. 423-437, 2009.

WANG, Y., VANHAVERBEKE, W., ROIJAKKERS, N. Exploring the impact of open innovation on national systems of innovation - A theoretical analysis. Technological Forecasting \& Social Change, v. 79, p. 419-428, 2012.

WEST, J., BOGERS, M. Leveraging External Sources of Innovation: A Review of Research of Open Innovation. The Journal of Product Innovation Management, v. 31(4), p. 814-831, 2014. 